\title{
Leukoplakia of Buccal Mucosa
}

National Cancer Institute

\section{Source}

National Cancer Institute. Leukoplakia of Buccal Mucosa. NCI Thesaurus. Code C8425.

A clinical term that indicates the presence of a white patch on the buccal mucosa in the mouth which cannot be characterized as any other disease. It may be a precancerous condition and in most cases histologic examination reveals keratosis. 